Scott Lang MD, David H. Johnson MD FRCPC, Dennis T. Lanigan DMD MD, Hang Ha MD FRCPC

\title{
Difficult tracheal extubation
}

We describe a case of nasotracheal tube fixation with a screw. A second case is described in which a broken drill bit was found to impinge on the wall but not penetrate into the lumen of a nasotracheal tube. Possible sequelae of this complication include airway leak, aspiration, tube obstruction, and trauma from attempts at forceful extubation. We recommend the routine intraoperative testing for tracheal tube movement and routine fibreoptic bronchoscopy through the tube when blind surgical procedures occur in the vicinity of a tracheal tube.

Anaesthetists are knowledgable in approaches to the difficult intubation. ${ }^{1}$ The difficult extubation is less common but can be equally as dangerous ${ }^{2-5}$ and even fatal. ${ }^{6}$ Tracheal tubes have been difficult to remove because of permanently inflated cuffs, ${ }^{7-9}$ tracheal tube laceration forming barbs, ${ }^{10}$ and fixation with Kirschner wires ${ }^{11-12}$ or sutures. ${ }^{13}$ The majority of cases of difficult extubations have been reported in association with orofacial surgery. We report the first case of a nasotracheal tube fixation with a Luhr plate screw. We also report a second case in which a possible nasotracheal tube fixation by a broken drill bit was excluded by fibreoptic bronchoscopy.

\section{Case 1}

A 17-year-old healthy female with Beckwith Wiedeman Syndrome required corrective surgery for a severe open bite malocclusion. She was scheduled for a Leforte I osteotomy with maxillary impaction, advancement, bone grafting and intermaxillary fixation. Anticipating a difficult airway, an awake bronchoscopic nasal intubation with local anaesthetic and IV sedation was planned. The intubation with a $6.5 \mathrm{~mm}$ nasal RAE tube was accom-

\section{Key words}

ANAESTHESIA TECHNIQUES: bronchoscopy, extubation; INTUBATION, TRACHEAL: complications, extubation; SURGERY: oral; sYNDROMES: Beckwith Wiedeman.

From the Departments of Anaesthesia and Dentistry, University of Saskatchewan Hospital, Saskatoon.

Address correspondence to: Dr. D. H. Johnson, Department of Anaesthesia, University Hospital, University of Saskatchewan, Saskatoon, Saskatchewan, Canada S7N 0X0. plished without difficulty. Maintenance anaesthesia with nitrous oxide-isoflurane-fentanyl was uneventful. The only surgical problem was placement of a screw in the Luhr plates securing the maxillae that was $2 \mathrm{~mm}$ longer than the desired length. The desired length of screw was not available at the time of surgery, and the next longer length was chosen to ensure adequate fixation in the piriform fossa. Tube mobility was not verified intraoperatively. As is our routine, the patient was transferred to the Intensive Care Unit for a planned extubation the morning after surgery. During the night, the nurse noted intermittent difficulty threading a suction catheter down the tracheal tube. When attempting to extubate the patient, it was noted that the tube was solidly fixed and could not be removed. Fibreoptic bronchoscopy revealed the distal end of a screw penetrating the nasotracheal tube (Figure 1). The patient was immediately returned to the Operating Room where under anaesthesia the screw was withdrawn sufficiently to allow for tube mobility. The patient was then successfully extubated upon awakening.

\section{Case 2}

A 22-year-old healthy male underwent corrective surgery for a midfacial retrusion and apertognathia secondary to posterior vertical maxillary excess. He was scheduled for a Leforte I osteotomy with impaction, advancement, bone grafting and intermaxillary fixation. Anaesthesia was induced with thiopentone-succinylcholine and the trachea was intubated nasally under direct vision with a soft PORTEX $7 \mathrm{~mm}$ tube. Maintenance anaesthesia with nitrous oxide-halothane-fentanyl was uneventful. During surgery, the surgeon noted that the drill bit had broken. A lateral face $x$-ray (Figure 2) located the drill bit seemingly impinging on the nasotracheal tube. Fibreoptic bronchoscopy verified an indentation but not penetration of the tube. The drill bit was not removed because of the extensive surgical dissection this would require. Tube mobility and deflation of cuff was verified and a second fibreoptic bronchoscopy done to ensure the tube movement had not caused the drill bit to now penetrate the tube. The patient was transferred to the ICU and successfully extubated without difficulty in the morning. One week later the broken drill bit fell out spontaneously.

\section{Discussion}

Our first case illustrates accidental surgical perforation 


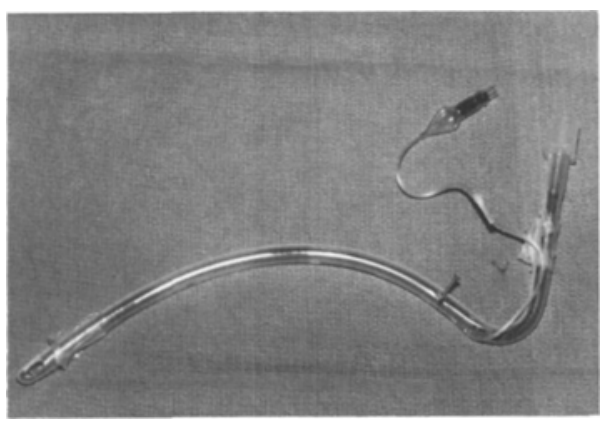

FIGURE 1 Luhr plate screw shown penetrating nasctracheal tube.

and fixation of a nasotracheal tube with a foreign body. Other authors have reported such occurrences with Kirschner wires ${ }^{11,12}$ or sutures. ${ }^{13}$ We supplement these reports with our case report of a surgically impaled tracheal tube by a screw. Tracheal tube perforation by a foreign body could result in an airway leak with concomitant lightening of anaesthesia, hypoxia, hypercarbia or deflation of the cuff with possible aspiration. In contrast, fixation of the tracheal tube can result in immediate and

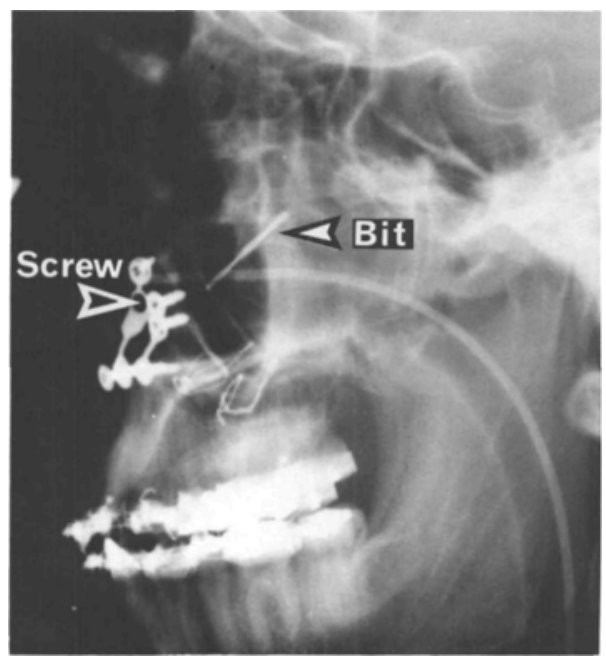

FIGURE 2 Lateral facial $x$-ray of Case 2 . Note proximity of normal screw position to nasotracheal tube. Drill bit end seemingly impinging on nasotracheal tube. delayed mechanical obstruction or trauma with vigorous attempts at extubation. ${ }^{6}$ Mechanical obstruction of the tracheal tube can occur by the occlusion caused with the foreign body itself. Furthermore, these foreign bodies increase the chance of retained secretions and can cause tube tenting and kinking or may obstruct the pilot tube preventing cuff deflation.

A mechanically obstructed tracheal tube that cannot be removed may present a life-threatening problem. A number of remedial therapies are possible. The cuff can be deflated allowing for spontaneous ventilation around the tracheal tube. Alternatively, a thin catheter can be passed beside the critical narrowing allowing for continuous inflow of oxygen or jet ventilation (deflate cuff to allow for expiration). A third possibility is the performance of a cricothyroidotomy through the trachea and nasotracheal tube.

Early recognition of a lacerated or fixed tracheal tube is of paramount importance to avoid further complications. Lee ${ }^{12}$ has suggested the routine testing of tracheal tube mobility at the end of all orthognathic surgery. Bhaskar ${ }^{1}$ recommends routine facial $x$-ray and passing a suction catheter down the tracheal tube when blindly directed Kirschner wires are used in orthognathic surgery. We feel that the availability of fibreoptic bronchoscopy allows an adaptation of these recommendations. The flexible bronchoscope will pass through even a nasal RAE tube. This is the first report to illustrate the use of bronchoscopy in localizing tracheal tube foreign bodies quickly and definitively. As seen in Figure 2, $x$-rays may not always demonstrate whether a foreign body is simply impinging on a tracheal tube or actually penetrating into its lumen. Our second case illustrates how fibreoptic bronchoscopy was used to differentiate between these two possibilities. Furthermore, we were able to reassess for possible lumen penetration caused by a tube mobility test. Fibreoptic bronchoscopy is the sole technique that would detect a sealed-over tube laceration before extubation with possible intranasal tube separation. We therefore recommend the routine intraoperative testing for tracheal tube movement and routine fibreoptic bronchoscopy through the tube when blind surgical procedures occur in the vicinity of a tracheal tube. If a fibreoptic bronchoscope is not available or cannot be passed down the tracheal tube because of size limitations, then $x$-ray, tracheal tube movement, and passage of a suction catheter down the tracheal tube are advisable.

\section{Acknowledgements}

The authors wish to thank Dr. Peter Duncan for his advice and Ms. B. Vercammen for her assistance in preparing the manuscript. 


\section{References}

1 Blanc VF, Tremblay NAG. The complications of tracheal intubation: a new classification with review of the literature. Anesth Analg 1974; 53: 202-13.

2 Tsueda K, Carey WJ, Gonty AA, Bosomworth PB. Hazards to anesthetic equipment during maxillary osteotomy: report of cases. J Oral Surgery 1977; 35: 47-9.

3 Peskin RM, Sachs SA. Intraoperative management of a partially severed endotracheal tube during orthognathic surgery. Anesthesia Progress 1986; 6: 247-51.

4 Pagar DM, Kupperman AW, Stern $M$. Cutting of nasoendotracheal tube: an unusual complication of maxillary osteotomies. J Oral Surgery 1978; 36: 314-5.

5 Mosby EL, Messner EJ, Nealis MF, Golden DP. Intraoperative damage to nasoendotracheal tubes during maxillary surgery: report of cases. J Oral Surgery 1978; 36: 963-4.

6 Dryden GE. Circulatory collapse after pneumonectomy (an unusual complication from the use of a Carlens catheter): case report. Anesth Analg 1977; 56: 451-2.

7 Tavakoli $M$, Corssen $G$. An unusual case of difficult extubation. Anesthesiology 1976; 45: 552-3.

8 Fagraeus L, Agngelillo JC, Dolan EA. A serious anesthetic hazard during orthognathic surgery. Anesth Analg 1980; 59: 150-3.

9 Fagraeus $L$. Difficult extubation following nasotracheal intubation. Anesthesiology 1978; 49: 43-4.

10 Schwartz LB, Sordill C, Liebers RM, Schwab W. Difficulty in removal of accidentally cut endotracheal tube. J Oral Maxillofac Surg 1982; 40: 518-5.

11 Bhaskar $P B, S$ chaffer $R B, D$ rummond $J N$. Bilateral fixation of a nasotracheal tube by transfacial Kirschner wires. J Oral Maxillofac Surg 1987; 45: 805-7.

12 Lee C, Schwartz S, Mok MS. Difficult extubation due to transfixation of a nasoendotracheal tube by a Kirschner wire. Anesthesiology 1977; 46: 427 .

13 Hilley $M D$, Henderson, $R B$, Giercke $A H$. Difficult extubation of the trachea. Anesthesiology 1983; 59: 149-50.

\section{Résumé}

On communique un cas de fixation du tube nasotrachéal par une vis. Un deuxième cas est décrit ou la meche brisée d'une perceuse s'est appuyée sur la paroi du tube nasotrachéal sans le percer. Les complications possibles sont les suivantes: perte d'air du tube nasotracheal, aspiration bronchique, obstruction du tube nasotrachéal et une lésion secondaire a une extubation traumatique. Nous recommendons que la mobilité du tube trachéal soit examinée de routine au cours de l'opération et qu'une bronchoscopie flexible soit faite de routine par le tube trachéal quand une procedure chirurgicale n'est pas faite sous vision directe dans la proximité d"un sube trachéal. 